\title{
In Vivo Investigation of Zr-Based Bulk Metallic Glasses Sub-Periosteally Implanted on the Bone Surface
}

\author{
Kazuhiro Imai \\ Department of Life Sciences, Graduate School of Arts and Sciences, The University of Tokyo, Tokyo, Japan \\ Email: imaik-ort@umin.ac.jp
}

Received 16 October 2015; accepted 5 January 2016; published 11 January 2016

\begin{abstract}
Bulk metallic glasses (BMG) show higher strength and lower Young's modulus than SUS 316L stainless steel and Ti-6Al-4V alloys. This study aimed to investigate the reaction of $\mathrm{Zr}$-based BMG sub-periosteally implanted on the surface of the rat femur, thereby evaluate the possibility of the BMG as biomaterials for osteosynthetic devices. $\mathrm{Zr}_{65} \mathrm{Al}_{7.5} \mathrm{Ni}_{10} \mathrm{Cu}_{17.5} \mathrm{BMG}$ ribbons with $10 \mathrm{~mm}$ length, $2 \mathrm{~mm}$ width and $0.5 \mathrm{~mm}$ thickness were implanted sub-periosteally on the femur surface in three male Wistar rats for 6 weeks. Systemic effects were evaluated by measuring $\mathrm{Cu}$ and Ni levels in the blood, and local effects were evaluated by the histological observation of the surrounding soft tissues in contact with the BMG. The reaction of the surface of the BMG was examined with scanning electron microscopy. No increase of $\mathrm{Cu}$ and $\mathrm{Ni}$ levels in the blood was recognized. In the scanning electron microscopy observation, spherical deposits which were considered as sodium chloride crystals were observed. Neither breakage nor pitting corrosion was noted. BMG will be a promising metallic biomaterial for osteosynthetic device that must be removed.
\end{abstract}

\section{Keywords}

Amorphous Alloy, Bulk Metallic Glasses, Biomaterial, Osteosynthetic Device

\section{Introduction}

For materials of osteosynthetic devices such as bone plates, intramedullary nails, and screws, crystalline metallic alloys such as SUS 316L stainless steel and Ti-6Al-4V alloys are commonly used. The materials need to possess non-toxicity, anti-corrosiveness, durability, strength, low Young's modulus and biocompatibility.

Bulk metallic glasses (BMG), i.e. amorphous alloys, are metallic materials with metastable glassy states. Tensile strength of the Zr-based BMG is 1500 - $1700 \mathrm{MPa}$ [1] and approximately twice higher than that of Ti-6Al-4V alloy and 3 times higher than that of 316L stainless steel. Young's modulus of the Zr-based BMG is 70 to $80 \mathrm{GPa}$ [1], which is closer to that of the bone than those of the conventional biomaterials.

$\mathrm{Zr}_{65} \mathrm{Al}_{7.5} \mathrm{Ni}_{10} \mathrm{Cu}_{17.5}$ BMG showed anti-corrosiveness behavior in the physiologically relevant environment [2]-[7] and $\mathrm{Zr}_{52.5} \mathrm{Cu}_{17.9} \mathrm{Ni}_{14.6} \mathrm{Al}_{10.0} \mathrm{Ti}_{5.0}$ BMG showed excellent electrochemical properties in the phosphatebuffered saline electrolyte [8]. However, the behaviors of Zr-based BMG have not been investigated so far by 
conducting an in vivo experiment.

The aim of this study was to investigate the reaction of Zr-based BMG sub-periosteally implanted on the surface of the rat femur, thereby evaluate the possibility of the BMG as biomaterials for osteosynthetic devices.

\section{Materials and Methods}

$\mathrm{Zr}_{65} \mathrm{Al}_{7.5} \mathrm{Ni}_{10} \mathrm{Cu}_{17.5}$ alloy ingots were prepared from a mixture of pure metals; zirconium, aluminum, nickel, and copper, each with a purity of more than $99.9 \%$. Each ingot was prepared by an arc melting method. The alloy was re-melted in a quartz nozzle and rapidly quenched by casting it on the rotating copper roll. BMG ribbon with $10 \mathrm{~mm}$ length, $2 \mathrm{~mm}$ width and $0.5 \mathrm{~mm}$ thickness was obtained. The structure of the formed alloy was analyzed by means of an $\mathrm{X}$-ray diffraction method with $\mathrm{Cu} \mathrm{K} \alpha$ radiation to ascertain that whole of the structure of the alloy was really amorphous. The free-side surface was polished with 600 grid silicon carbide paper in distilled water, dried for a few days to generate air-formed passive film, and then were sterilized in a high-pressure steam sterilizer (BS-305; TOMY, Tokyo, Japan). It was confirmed that none of these preparation procedures had any influence on the amorphous structure of the alloy.

In vivo experiment was approved by the animal committee in our institution based on the result of the study showing excellent anti-corrosiveness in the simulated body fluid [2]-[7]. Fourteen-week-old male Wistar rats were used in the experiment. Each animal was housed in a separated cage (22 cm $\times 33 \mathrm{~cm} \times 13 \mathrm{~cm}$ height $)$ and received a standard diet. Six rats weighing 400 to 450 grams were randomly assigned into two groups. The $\mathrm{Zr}_{65} \mathrm{Al}_{7.5} \mathrm{Ni}_{10} \mathrm{Cu}_{17.5}$ BMG ribbon was implanted sub-periosteally on the femur surface in 3 rats (Figure 1). The other 3 rats were assigned as control group.

Under intraperitoneal anesthesia with $75 \mathrm{mg} / \mathrm{kg}$ of ketamine hydrochloride and $10 \mathrm{mg} / \mathrm{kg}$ of xylazine, the left mid-shaft of femur was exposed between the vastus lateralis and hamstrings and BMG ribbon was implanted sub-periosteally on the surface of the femur of each rat. For preventing migration of the alloy, it was tied up both proximally and distally on the surface of the femur with a 4 - 0 nylon suture string (Figure 2). A sham operation was performed on the contra-lateral right femur. The wound was irrigated with normal saline and then was closed by each layer suture. Postoperatively, each animal was allowed free activity in a separate cage.

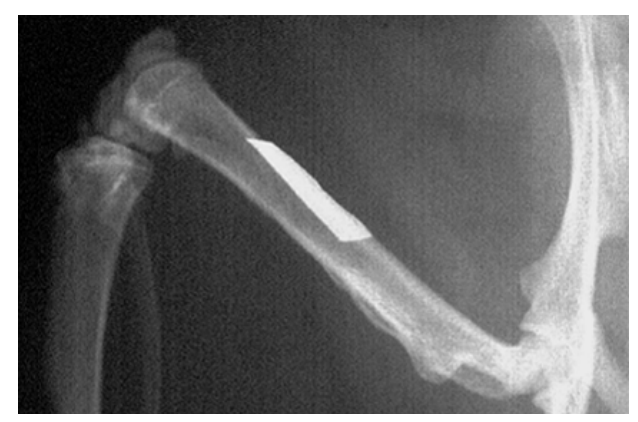

Figure 1. Radiograph of the femur with the BMG ribbon sub-periosteally implanted on the bone surface.

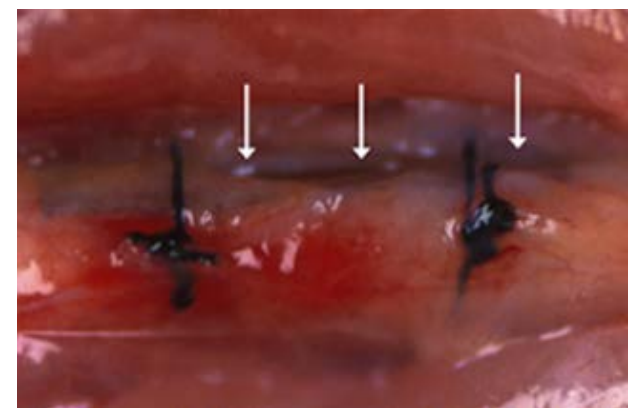

Figure 2. Photograph of the femur with the BMG ribbon (arrows) sub-periosteally implanted and tied up both proximally and distally with a 4 - 0 nylon suture string after 6 weeks implantation. 
After 6 weeks from implantation, $5 \mathrm{ml}$ of blood samples was obtained from the descending aorta under anesthesia with intra-peritoneal injection of $45 \mathrm{mg} / \mathrm{kg}$ of ketamine hydrochloride and $6 \mathrm{mg} / \mathrm{kg}$ of xylazine to measure blood level of $\mathrm{Cu}$ and Ni. Then, euthanasia with intra-peritoneal injection of $120 \mathrm{mg} / \mathrm{kg}$ of ketamine hydrochloride and $16 \mathrm{mg} / \mathrm{kg}$ of xylazine, the BMG ribbon was removed. Undecalcified specimens of the femur, periosteum, and surrounding soft tissues that were in contact with the BMG ribbon were prepared and stained with Hematoxylin-Eosin.

The extracted BMG ribbons were lavaged for 20 second with $30 \mathrm{ml}$ of UF detergent in purified water and were fixed by a carbon tape and preserved in an airtight container. The surface of the BMG that had been in contact with the femora were observed by a scanning electron microscopy (XL30FEG, Philips) and constituents of the material formed on the surface of the alloys were identified and semi-quantified by energy dispersive X-ray spectroscopy (DX-4, EDAX Japan, Tokyo).

\section{Results}

\subsection{Cu and Ni Blood Levels}

In the investigation on the systemic effects of BMG group, the mean whole-blood Cu concentration was $101.3 \pm$ $6.1 \mu \mathrm{g} / \mathrm{dl}$ and the mean whole-blood $\mathrm{Ni}$ concentration was less than $0.10 \mu \mathrm{g} / \mathrm{dl}$. In control group, the mean whole-blood $\mathrm{Cu}$ concentration was $117.3 \pm 11.2 \mu \mathrm{g} / \mathrm{dl}$ and the mean whole-blood $\mathrm{Ni}$ concentration was less than $0.10 \mu \mathrm{g} / \mathrm{dl}$. No increase of the blood levels of $\mathrm{Cu}$ and $\mathrm{Ni}$ was recognized in BMG group in comparison to those of control group.

\subsection{Histological Findings}

The observation by light microscopy of the H\&E stained specimens of the surrounding soft tissues in contact with the BMG disclosed that no findings of the biological effects was recognized such as bone resorption, infiltration of inflammatory cells, cell necrosis or dysplasia, wear debris of the alloy and so on (Figure 3).

\subsection{Surface Analysis of the Implanted Materials}

Surface observation by scanning electron microscopy (SEM) revealed spherical deposits (Figure 4). Transverse grooves that would be made by polished with 600 grid $\mathrm{SiC}$ paper were observed both before implantation and after 6 weeks implantation. The semi-quantitative examination of the constituents of the surface materials formed on the alloy surface by energy dispersive spectroscopy (EDS) disclosed that $\mathrm{Na}$ and $\mathrm{Cl}$ were recognized (Figure 5). Therefore, the spherical deposits were considered as sodium chloride crystals. Neither breakage nor pitting corrosion of the harvested BMG was noted (Figure 6).

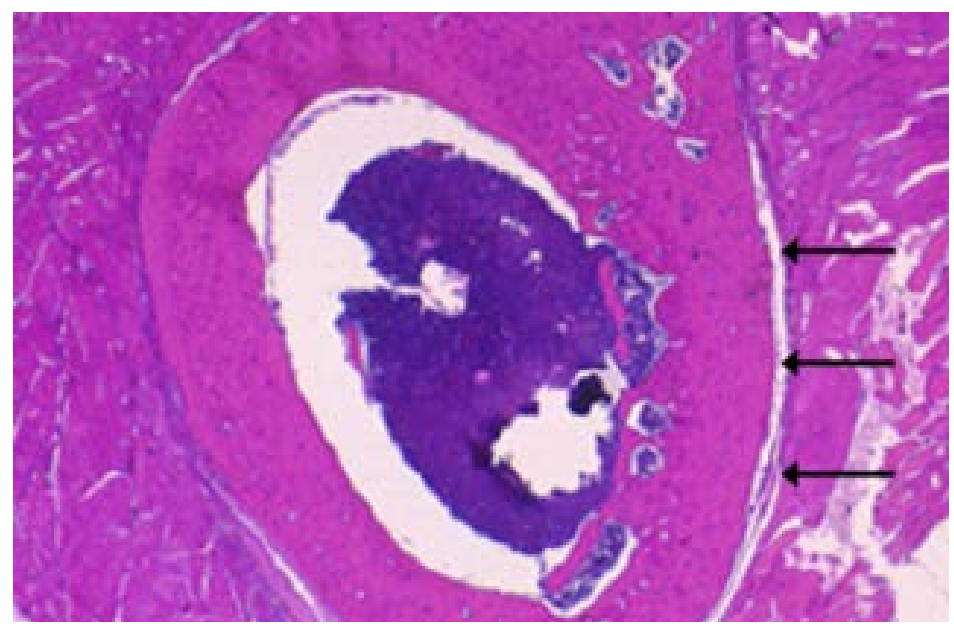

Figure 3. Photomicrograph of the femur and the surrounding soft tissues after 6 weeks implantation and removal of the BMG. The BMG ribbon had been implanted sub-periosteally (arrows). H \& E, $\times 10$. 


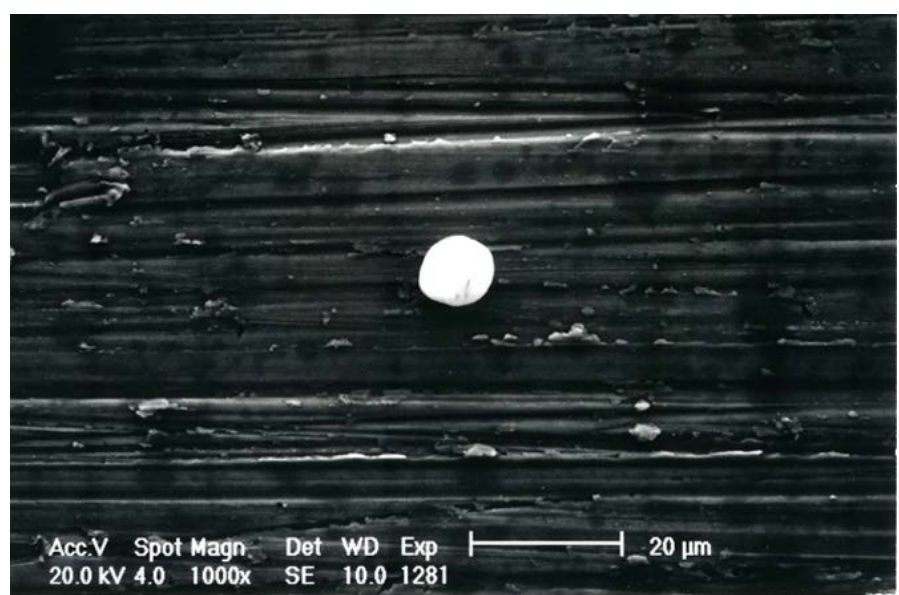

Figure 4. Surface appearance of the extracted BMG after 6 weeks implantation. Scanning electron microscopy (SEM), $\times 1000$.

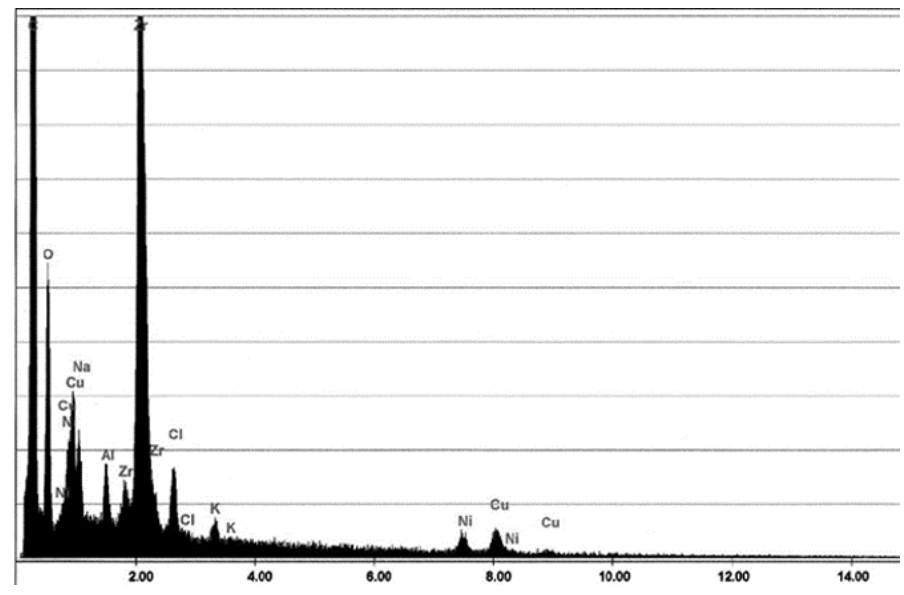

Figure 5. Energy dispersive spectroscopy (EDS) of the surface of the BMG after 6 weeks implantation. The constituents of the surface materials included $\mathrm{Na}$ and $\mathrm{Cl}$.

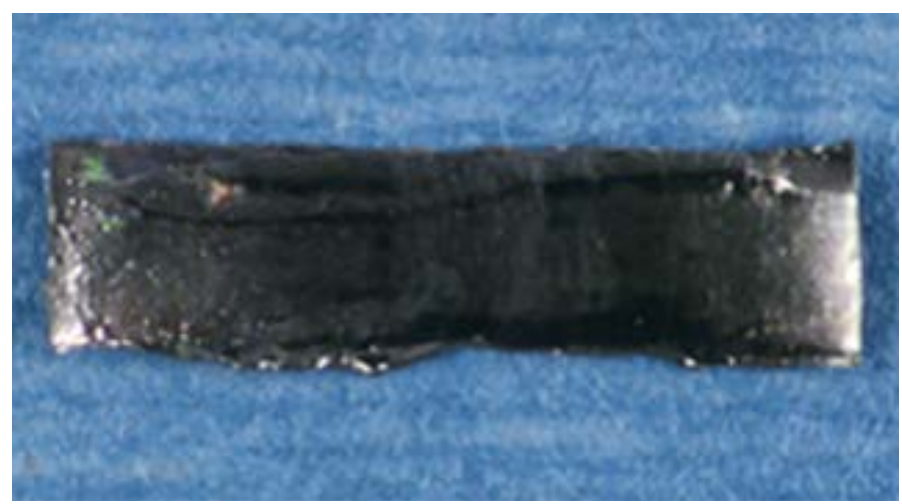

Figure 6. The extracted BMG ribbon. This photo shows the side that had been in contact with the femur.

\section{Discussion and Conclusion}

Current osteosynthetic devices made of SUS 316L stainless steel and Ti-6Al-4V titanium alloy sometimes failed due to their insufficient strength. According to the survey on orthopaedic implant failure by the implant com- 
mittee of the Japanese Orthopaedic Association, 2.5\% of the osteosynthetic implants failed [9]. To prevent failure, the bone plates have inevitably been made bulky and extensive surgical exposure is necessary to implant such plates. Occasionally it leads difficulty in closing the open wound. Therefore, one of the disadvantages of the current metallic osteosynthetic devices is their insufficient strength. Another disadvantage is their excessively higher Young's modulus. The Young's moduli of currently available metallic devices are $100 \mathrm{GPa}$ ordered and much higher than that of cortical bone, i.e., $20 \mathrm{GPa}$. This sometimes causes stress shielding and absorption of the bone stabilized with osteosynthetic devices made of these materials [10]-[14].

BMG, i.e. amorphous alloys, are materials with no long-range atomic order that are prepared by the solidification of a liquid melt at a sufficient rate to suppress the growth of crystalline phases. Conventional metallic biomaterials such as Ti-6Al-4V alloys and 316L stainless steel are crystalline alloys. Crystalline alloys have grain boundaries, dislocations, and segregations. When the crystalline alloys are loaded, grain boundaries and dislocations easily lead failure. In addition, crystalline alloys have slip plane formed by shearing stress, which results in plastic deformation of the material via translocation of the structure.

On the contrary, BMG have random atom structure and do not have segregations and defects in their structure. In BMG, no slip plane is generated and elastic deformation continues even under considerably large stress because the deformation is caused by massive movement of the atoms. On this account, BMG show higher strength and lower Young's modulus than crystalline alloys. In this way, BMG have some advantages for metallic biomaterials.

In the previous literatures, there had been only two studies that evaluated BMG in vivo [15] [16]. There had been another paper that reported metallic intravascular stent with amorphous oxide surface showed excellent corrosion resistance not only in vitro but also in vivo [17]. Our investigation was the first to implant BMG subperiosteally on the bone surface in vivo.

In this study, we used a Zr-based BMG containing nickel that was referred to as carcinogenic. No systemic and local effects were recognized by measuring $\mathrm{Cu}$ and $\mathrm{Ni}$ levels in the blood and the histological observation of the surrounding soft tissues in contact with the BMG. But nickel free materials might be more appropriate for biomaterials and nickel free $\mathrm{Zr}-\mathrm{Al}-\mathrm{Cu} \mathrm{BMG}$ is available now. The future study should investigate nickel free Zr-Al-Cu BMG.

The SEM and EDS results in this study indicated that $\mathrm{Zr}_{65} \mathrm{Al}_{7.5} \mathrm{Ni}_{10} \mathrm{Cu}_{17.5} \mathrm{BMG}$ was almost biologically inert. The excellent biocompatibility of titanium and its alloys may result in osseous integration and strong bone-tometal attachment may cause complications. The detaching test after implantation of the Ti-6Al-4V plates into the tibiae of rabbits indicated that the Ti alloy bonds directly to bone after more than 8 weeks [18]. Therefore, biomaterials with low reactivity in vivo like $\mathrm{Zr}_{65} \mathrm{Al}_{7.5} \mathrm{Ni}_{10} \mathrm{Cu}_{17.5} \mathrm{BMG}$ might be more appropriate for osteosynthetic device that must be removed.

The problems exist in adopting this material for clinical application. One is that large sized BMG are technically demanding to create. Applying BMG for osteosynthetic devices, even larger sized material should be manufactured. Another problem is that there is no data about non-toxicity, anti-corrosiveness, and durability with long term implantation. In conclusion, BMG will be a promising metallic biomaterial for new osteosynthetic implants but further in vivo study should be necessary.

\section{References}

[1] Inoue, A., Zhang, T. and Masumoto, T. (1995) Preparation of Bulky Amorphous Zr-Al-Ni-Cu Alloys by Copper Mold Casting and Their Thermal and Mechanical Properties. Materials Transactions JIM, 36, 391-398.

[2] Hiromoto, S., Asami, K., Tsai, A-P., Sumita, M. and Hanawa, T. (2002) Surface Composition and Anodic Polarization Behavior of Zirconium-Based Amorphous Alloy with Various Alloying Elements in a Phosphate Buffered Saline Solution. Journal of Electrochemical Society, 149, B117-B122. http://dx.doi.org/10.1149/1.1456921

[3] Hiromoto, S. and Hanawa, T. (2002) Re-Passivation Current of Amorphous Zr65Al7.5Ni10Cu17.5 Alloy in a Hanks' Balanced Solution. Electrochimica Acta, 47, 1343-1349. http://dx.doi.org/10.1016/S0013-4686(01)00876-3

[4] Hiromoto, S., Tsai, A.-P., Sumita, M. and Hanawa, T. (2000) Effect of Chloride Ion on the Polarization Behavior of the Zr65Al7.5Ni10Cu17.5 Amorphous Alloy in Phosphate Buffered Solution. Corrosion Science, 42, 1651-1660. http://dx.doi.org/10.1016/S0010-938X(00)00022-6

[5] Hiromoto, S., Tsai, A.-P., Sumita, M. and Hanawa, T. (2000) Effect of Surface Finishing and Dissolved Oxygen on the Polarization Behavior of Zr65Al7.5Ni10Cu17.5 Amorphous Alloy in Phosphate Buffered Solution. Corrosion Science, 42, 2167-2185. http://dx.doi.org/10.1016/S0010-938X(00)00043-3 
[6] Hiromoto, S., Tsai, A.-P., Sumita, M. and Hanawa, T. (2000) Effect of pH on the Polarization Behavior of $\mathrm{Zr}_{65} \mathrm{Al}_{7.5} \mathrm{Ni}_{10} \mathrm{Cu}_{17.5}$ Amorphous Alloy in a Phosphate Buffered Solution. Corrosion Science, 42, 2193-2200. http://dx.doi.org/10.1016/S0010-938X(00)00056-1

[7] Hiromoto, S., Tsai, A-P., Sumita, M. and Hanawa, T. (2002) Surface Characterization of Zr-Al-(Ni, Cu) Amorphous Alloys Immersed in a Cell-Culture Medium. Materials Transactions JIM, 43, 261-266.

[8] Morrison, M.L., Buchanan, R.A., Leon, R.V., Liu, C.T., Green, B.A., Liaw, P.K., et al. (2005) The Electrochemical Evaluation of a Zr-Based Bulk Metallic Glass in a Phosphate-Buffered Saline Electrolyte. J Biomed Mater Res A, 74, 430-438. http://dx.doi.org/10.1002/jbm.a.30361

[9] Implant Committee of the Japanese Othopaedic Association (2000) Report of the Implant Survey. J. Jpn Orthop Assoc, 74, 525-534. (In Japanese)

[10] Molster, A.O. (1986) Biomechanical Effects of Intramedullary Reaming and Nailing on Intact Femora in Rats. Clin Orthop, 202, 278-285.

[11] Uhthoff, H.K. and Dubuc, F.L. (1971) Bone Structure Changes in the Dog under Rigid Internal Fixation. Clin Orthop, 81, 165-170. http://dx.doi.org/10.1097/00003086-197111000-00026

[12] Bradley, G.W., McKenna, G.B., Dunn, H.K., Daniels, A.U. and Statton, W.O. (1979) Effects of Flexural Rigidity of Plates on Bone Healing. J Bone Joint Surg Am, 61, 866-872.

[13] Woo, S.L., Akeson, W.H., Coutts, R.D., Rutherford, L., Doty, D., Jemmott, G.F., et al. (1976) A Comparison of Cortical Bone Atrophy Secondary to Fixation with Plates with Large Differences in Bending Stiffness. J Bone Joint Surg Am, 58, 190-195.

[14] Tonino, A.J., Davidson, C.L., Klopper, P.J. and Linclau, L.A. (1976) Protection from Stress in Bone and Its Effects. Experiments with Stainless Steel and Plastic Plates in Dogs. J Bone Joint Surg Br, 58, 107-113.

[15] Oonishi, H., Tsuji, E., Nabeshima, T., Kushitani, S., Tsuyama, K., Ukon, Y., et al. (1987) In Vitro and in Vivo Reactions of Various Amorphous Metals. Biomaterials and Clinical Applications, 541-546.

[16] Imai, K. and Hiromoto, S. (2014) In Vivo Evaluation of Zr-Based Bulk Metallic Glass Alloy Intramedullary Nails in Rat Femora. J Mater Sci Mater Med, 25, 759-768. http://dx.doi.org/10.1007/s10856-013-5102-3

[17] Shih, C.C., Lin, S.J., Chung, K.H., Chen, Y.L. and Su, Y.Y. (2000) Increased Corrosion Resistance of Stent Materials by Converting Current Surface Film of Polycrystalline Oxide into Amorphous Oxide. J Biomed Mater Res, 52, 323332. http://dx.doi.org/10.1002/1097-4636(200011)52:2<323::AID-JBM11>3.0.CO;2-Z

[18] Takatsuka, K., Yamamuro, T., Nakamura, T. and Kokubo, T. (1995) Bone-Bonding Behavior of Titanium Alloy Evaluated Mechanically with Detaching Failure Load. J Biomed Mater Res, 29, 157-163. http://dx.doi.org/10.1002/jbm.820290204 